\title{
ESTIMATING CONCRETE STRENGTH USING THE CORRELATION OF THE CONCRETE MATURITY METHOD APPLIED TO THE MATERIALS OF COCHABAMB A-B OLIVIA
}

Jonathan Hugo Vargas Blaschke and Francisco Aguirre Torrico

\begin{abstract}
In order to estimate concrete strength, concrete cylinders are commonly used; however, this method, although widely accepted, does not produce immediate results and due to the vast amounts of variables that exist, may or may not be an accurate depiction of the real, in place concrete strength. This article seeks to apply the maturity method to the Bolivian environment of construction and aims to produce an analytical model for concrete maturity in Bolivia by finding the relationship between the concrete's internal temperature and the curing time in order to determine the exact resistance and strength of the concrete at hand. The results will then be validated by and compared to concrete cylinders of the same mix and characteristics. The method was tested on the seventh floor of the residential building "Terrazas de Aranjuez". All the tests that were necessary prior to the application were conducted at READY MIX laboratories Cochabamba. A specific mix of $21 \mathrm{MPa}$ strength concrete was prepared and then tested. The maturity method allows the exact moment the concrete reaches its required resistance to be known. The required concrete resistance was reached 11 days after the pouring of the concrete. This implied that a complete removal of framework could be done between 11-14 days after the pour considering that minor differences exist between the readings of each sensor positioned in the slab. This method not only reduces construction time and costs but also allows a precise and immediate knowledge of the concrete resistance.
\end{abstract}

Keywor ds: Concrete Strength, Maturity Index, Datum Temperature.

DOI: $10.23881 /$ idupbo.018.1-9i 